\title{
Duplex Color Doppler Evaluation of Retinal Arterial Blood Flow in Type 2 Diabetic Subjects without Retinopathy
}

\author{
Mashah Binte Amin ${ }^{1}$, Farzana Shegufta ${ }^{2}$, Md. Towhidur Rahman ${ }^{3}$, Tarana Yasmin ${ }^{4}$, \\ Khaleda Parvin Rekha ${ }^{5}$, A. S. Mohiuddin 6 \\ Received: May 24, 2014 Accepted: June 20, 2014
}

\begin{abstract}
Background: Diabetic retinopathy is a vascular disorder affecting the microvasculature of retina. It is caused by changes in the blood vessels of retina. If untreated, it may lead to blindness which is usually preventable if retinopathy is diagnosed early and treated promptly. In ophthalmology, color Doppler imaging is a new method that enables us to assess the orbital vasculature. It allows for simultaneous two dimensional anatomical and Doppler evaluations of hemodynamic characteristics of retinal artery. Objective: To observe the difference between Doppler flow velocity indices (peak systolic velocity, end diastolic velocity and resistive index) of retinal artery in type 2 diabetic subjects without retinopathy and those of normal controls. Materials and Methods: This case-control study was carried out in the department of Radiology and Imaging, Bangladesh Institute of Research and Rehabilitation in Diabetes, Endocrine and Metabolic Disorders (BIRDEM) in collaboration with Ophthalmology Outpatient Department, BIRDEM, Dhaka from July 2011 to June 2013. Eighty diabetic patients without retinopathy aged 27-68 years were enrolled as cases and age and sex matched 80 healthy subjects were selected as controls. Type 1 diabetic patients, type 2 diabetics with retinopathy, hypertensive and dyslipidemic subjects were excluded from the study. All the selected subjects underwent duplex Doppler ultrasonography of both eyes using 5 to $7.5 \mathrm{MH}$ linear phase transducer. Duplex color Doppler findings including spectral analysis (PSV, EDV and RI) were recorded. Unpaired t test was done to compare blood flow velocity indices of retinal artery in type 2 diabetic patients without retinopathy and that of healthy control subjects. $p$ value $<0.05$ was considered as significant. Results: Majority $(42.5 \%$ and $47.5 \%$ ) of subjects were in $4^{\text {th }}$ decade of life in both groups with predominance of males. The mean duration of diabetes was $4.56 \pm 2.1$ years. Mean peak systolic velocity (PSV) in 80 diabetic patients without retinopathy was $10.70 \pm 1.50 \mathrm{~cm} / \mathrm{sec}$ ranging $5.30-16.10 \mathrm{~cm} / \mathrm{sec}$ and that of 80 healthy subjects was $11.27 \pm 0.98 \mathrm{~cm} / \mathrm{sec}$ ranging $9.0-13.10 \mathrm{~cm} / \mathrm{sec}$. Mean end diastolic velocity $(E D V)$ in 80 diabetic patients without retinopathy was $2.58 \pm 0.67 \mathrm{~cm} / \mathrm{sec}$ ranging $1.00-5.10$ $\mathrm{cm} / \mathrm{sec}$ and that of 80 healthy subjects was $4.11 \pm 2.7 \mathrm{~cm} / \mathrm{sec}$ ranging $3.00-4.60 \mathrm{~cm} / \mathrm{sec}$. Mean resistive index (RI) in 80 diabetic patients without retinopathy was $0.75 \pm 0.04$ ranging $0.66-0.81$ and that of 80 healthy subjects was $0.64 \pm 0.02$ ranging $0.60-0.70$. Mean difference of retinal arterial RI of diabetic subjects without retinopathy and healthy control eyes was statistically significant $(p<0.001)$. Conclusion: From the present study it can be concluded that, there is statistically significant difference between retinal arterial RI of type 2 diabetic patients without retinopathy and that of healthy control adult subjects.
\end{abstract}

Key words: Retinopathy; Ultrasonography; Type 2 DM; Duplex color Doppler

J Enam Med Col 2014; 4(3): 168-173

1. Assistant Professor, Department of Radiology and Imaging, Enam Medical College \& Hospital, Savar, Dhaka

2. Junior Consultant, Department of Radiology and Imaging, Bangladesh Institute of Research and Rehabilitation in Diabetes, Endocrine and Metabolic Disorders (BIRDEM), Dhaka

3. Medical Officer, Department of Radiology and Imaging, BIRDEM, Dhaka

4. Assistant Professor, Department of Radiology and Imaging, Enam Medical College \& Hospital, Savar, Dhaka

5. Assistant Professor, Department of Radiology and Imaging, North East Medical College \& Hospital, Sylhet

6. Senior Consultant, Department of Radiology and Imaging, BIRDEM, Dhaka

Correspondence Mashah Binte Amin,Email: mashah.amin@gmail.com 


\section{Introduction}

Diabetes mellitus is one of the most common noncommunicable diseases globally. The prevalence of diabetes for all age groups worldwide has been estimated to be $6.4 \%$, affecting 285 million adults in $2010 .{ }^{1}$ Bangladesh is a developing country that has been facing a high prevalence of diabetes mellitus. In 2011, 8.4 million of people with diabetes have been estimated in our country with prevalence of $8.1 \%$ in urban and $2.3 \%$ in rural areas. ${ }^{2-3}$

As the prevalence of diabetes is rising, the systemic complications that include retinopathy, nephropathy and neuropathy and involvement of cardiovascular system are also increasing. ${ }^{4}$ Diabetic retinopathy is a vascular disorder affecting the microvasculature of retina. It is caused by changes in the blood vessels of retina. If untreated, it may lead to blindness. Therefore, if diagnosed and treated promptly, blindness is usually preventable. ${ }^{5-7}$

In ophthalmology, color Doppler imaging is a new method that enables us to assess the orbital vasculature. It allows for simultaneous two dimensional anatomical and Doppler evaluations of hemodynamic characteristics of retinal artery. ${ }^{8-13}$ Standard ophthalmoscopy can detect retinal abnormalities, but after the development of retinopathy and it is very much observer dependent. ${ }^{14-16}$ On the other hand, slit-lamp biomicroscopy can assess retinal changes, but it is very much time consuming and needs pupillary dilatation which causes discomfort to patient. ${ }^{17-18}$ Retinal arterial hemodynamic changes can also be assessed by the gold standard fluorescein dye-dilution technique, but accurate measurement of staining after intravenous injection of fluorescein is difficult at retinal arterial level. Therefore, duplex color Doppler ultrasonography is the investigation of choice for qualitative and quantitative assessment of retinal arterial blood flow velocities very quickly without any invasive procedure. ${ }^{19-21}$

Diabetic retinopathy is the leading cause of blindness. As the prevalence of diabetes is rising, the incidence of retinopathy is increasing day by day. For diagnosis of early changes in retinal blood flow in DM without retinopathy duplex color Doppler ultrasonography is the investigation of choice to assess the problem very quickly without any invasive procedures. Thus, this would be a beneficial tool for the ophthalmologist to assess and make quick decision about patient with impaired blood flow and to take necessary actions. Therefore, we designed this study in our population to assess the different Doppler flow velocity indices of retinal arteries.

\section{Materials and Methods}

This case-control study was conducted on both eyes of 160 subjects aged 27-68 years in the department of Radiology and Imaging, Bangladesh Institute of Research and Rehabilitation in Diabetes, Endocrine and Metabolic Disorders (BIRDEM) from July 2011 to June 2013. Patients with type 2 diabetes without retinopathy (normal findings in slit lamp biomicroscopy) were referred from Ophthalmology OPD, BIRDEM to the department of Radiology and Imaging for duplex color Doppler study of eyes. Among them 80 diabetic patients without retinopathy were enrolled as cases and age and sex matched 80 healthy subjects with normal ophthalmology examination findings were taken as controls. Patients with hypertension and dyslipidemia were excluded. The objective of the study was discussed in details with the patients before enrollment. Demographic information was recorded and substantiated by means of inspection of medical record. Information included the subject's age, sex, medical and surgical history, clinical history of diabetes, followed by duplex color Doppler study with spectral analysis. The color Doppler study was performed first by the investigator herself and subsequently confirmed by a radiologist of the department of Radiology and Imaging, BIRDEM who was not informed of the subject's condition to eliminate bias. Peak systolic velocity (PSV), end diastolic velocity (EDV) and resistive index (RI) of retinal arteries were recorded from both right and left eyes. Duplex color Doppler sonography of retinal arteries was also carried out in control group after informing them about the purpose of the study. PSV, EDV and RI were also measured in both eyes in control group. PSV, EDV and RI values of retinal artery of both groups were compared.

All the relevant collected data were compiled on a master chart first, then organized by using scientific calculator and standard statistical formulas. Percentage was calculated to find out the proportion of the findings. 
Further statistical analysis of the results was done by SPSS version 17.0. Comparison between the velocity indices in diabetic patients without retinopathy and normal control individuals was done by the unpaired student $t$ test. $\mathrm{p}$ value $<0.05$ was considered significant.

\section{Results}

Mean age of the diabetic patients was $46.05 \pm$ 9.78 years with range from 27-68 years. Among them 58.7\% were male and $41.3 \%$ were female. Most of the patients (42.5\%) were found in $4^{\text {th }}$ decade. On the other hand, the mean age of healthy control subjects was $42.78 \pm 7.31$ years with range from $30-59$ years. Among them $53.7 \%$ were male and $46.3 \%$ were female. Majority (47.5\%) were found in $4^{\text {th }}$ decade. The mean duration of diabetes was $4.56 \pm 2.1$ years. The study also reveals that there was no significant difference $(p>0.05)$ in retinal arterial mean PSV, mean EDV and mean RI between right and left eyes of diabetic patients without retinopathy and also in control subjects.

In the current study, it was found that the mean PSV in diabetic patients without retinopathy was $10.70 \pm 1.50 \mathrm{~cm} / \mathrm{sec}$ ranging $5.30-16.10$ $\mathrm{cm} / \mathrm{sec}$ and the mean PSV measured in healthy subjects was $11.27 \pm 0.98 \mathrm{~cm} / \mathrm{sec}$ ranging $9.00-13.10 \mathrm{~cm} / \mathrm{sec}$ (Table I).

In the present study, it was also found that the mean EDV in diabetic patients without retinopathy was $2.58 \pm 0.67 \mathrm{~cm} / \mathrm{sec}$ ranging $1.00-5.10 \mathrm{~cm} / \mathrm{sec}$ and the mean EDV measured in healthy subjects was $4.11 \pm 2.7 \mathrm{~cm} / \mathrm{sec}$ ranging $3.00-4.60 \mathrm{~cm} / \mathrm{sec}$ (Table II).

In this study the mean differences of retinal arterial PSV and EDV in diabetic eyes without retinopathy and healthy control eyes was statistically significant $(\mathrm{p}<0.01)$.

In the current study, it was found that the mean RI in 80 diabetic patients without retinopathy was $0.75 \pm 0.04$ ranging $0.66-0.81$. And the mean RI value measured in 80 healthy subjects was $0.64 \pm 0.02$ ranging $0.60-0.70$. The mean difference was statistically significant $(\mathrm{p}<0.001)$ between two groups (Table III).

Spectral Doppler flow patterns of retinal arteries of both eyes in a normal control subject and a type 2 diabetic subject are shown in Figures 1, 2, 3 and 4.

Table I: Comparison between mean peak systolic velocity of retinal artery of 160 control eyes and 160 diabetic patients' eyes without retinopathy $(n=320)$

\begin{tabular}{|l|c|c|c|c|}
\hline Groups & Mean $(\mathrm{cm} / \mathrm{sec})$ & Range $(\mathrm{cm} / \mathrm{sec})$ & t value & $\mathrm{p}$ value \\
\hline $\begin{array}{c}\text { Control group } \\
(\mathrm{n}=160)\end{array}$ & $11.27 \pm 0.98$ & $9.00-13.10$ & & \\
\hline $\begin{array}{c}\text { Diabetic group } \\
(\mathrm{n}=160)\end{array}$ & $10.70 \pm 1.50$ & $5.30-16.10$ & & $<0.01$ \\
\hline
\end{tabular}

$\mathrm{p}$ value was achieved from unpaired $t$ test

Table II: Comparison between mean end diastolic velocity of retinal arteries of 160 control eyes and 160 diabetic patients' eyes without retinopathy $(n=320)$

\begin{tabular}{|c|c|c|c|c|}
\hline Groups & Mean $(\mathrm{cm} / \mathrm{sec})$ & Range $(\mathrm{cm} / \mathrm{sec})$ & t value & $\mathrm{p}$ value \\
\hline $\begin{array}{c}\text { Control group } \\
(\mathrm{n}=160)\end{array}$ & $4.11 \pm 2.7$ & $3.00-4.60$ & & \\
\hline $\begin{array}{c}\text { Diabetic group } \\
(\mathrm{n}=160)\end{array}$ & $2.58 \pm 0.67$ & $1.00-5.10$ & & \\
\hline
\end{tabular}

$\mathrm{p}$ value was achieved from unpaired $t$ test

Table III: Comparison of retinal arterial mean resistive index (RI) between 160 control eyes and 160 diabetic patients' eyes without retinopathy $(n=320)$

\begin{tabular}{|l|l|l|l|l|}
\hline Groups & Mean \pm SD & Range & t value & $p$ value \\
\hline $\begin{array}{c}\text { Control group } \\
(\mathrm{n}=160)\end{array}$ & $0.64 \pm 0.02$ & $0.60-0.70$ & & \\
\hline $\begin{array}{c}\text { Diabetic group } \\
(\mathrm{n}=160)\end{array}$ & $0.75 \pm 0.04$ & $0.66-0.81$ & & \\
\hline
\end{tabular}

$\mathrm{p}$ value was achieved from unpaired $t$ test 


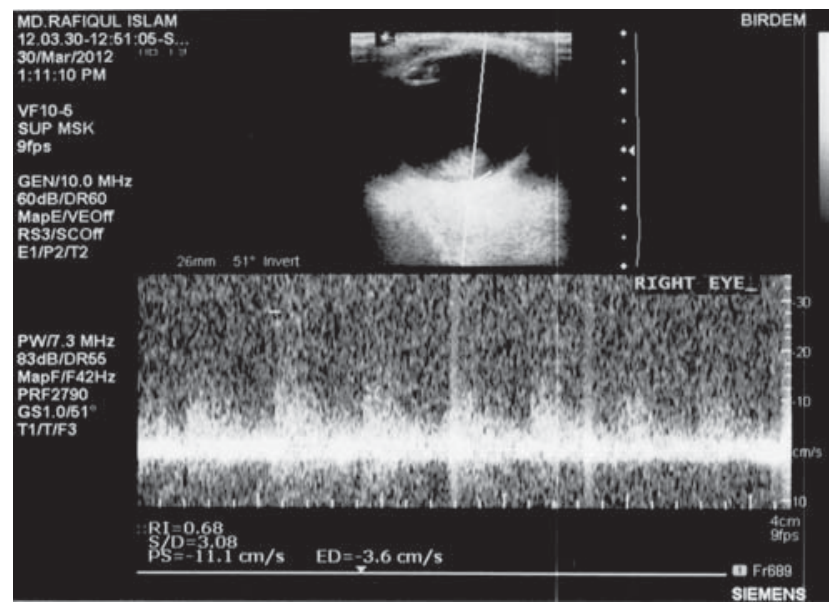

Fig 1. Spectral Doppler flow patterns of retinal artery of right eye in a normal control subject

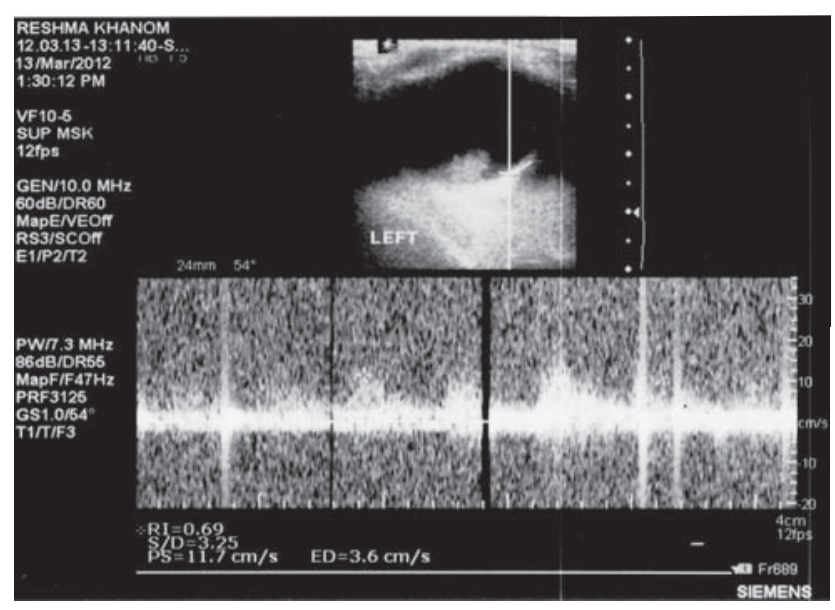

Fig 3. Spectral Doppler flow patterns of retinal artery of left eye in a normal control subject

\section{Discussion}

As the prevalence of diabetes is rising, the systemic complications that include retinopathy, nephropathy, neuropathy and involvement of cardiovascular system are also increasing. Diabetic retinopathy is the leading cause of blindness in the world. Prevention of retinopathy needs early diagnosis. ${ }^{22}$ Despite the improvement in ophthalmoscopic examination in outpatient department (OPD) in Ophthalmology, in order to diagnose early changes in retinal arterial flow velocity, a newer imaging modality may be used for diagnosis of early changes in retinal artery before clinical manifestation of retinopathy.

Color Doppler imaging is the most promising modality that produces conventional gray-scale ultrasound

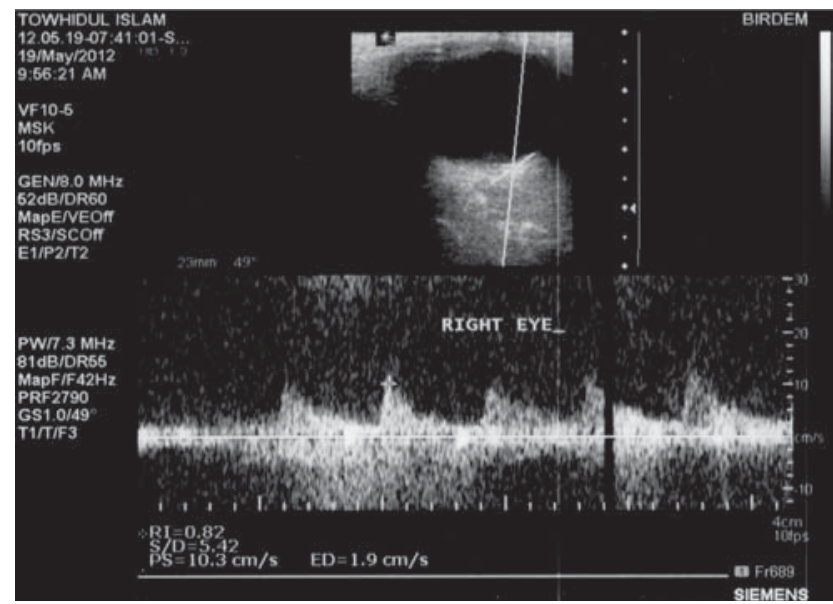

Fig 2. Spectral Doppler flow patterns of retinal artery of right eye in a type 2 diabetic subject

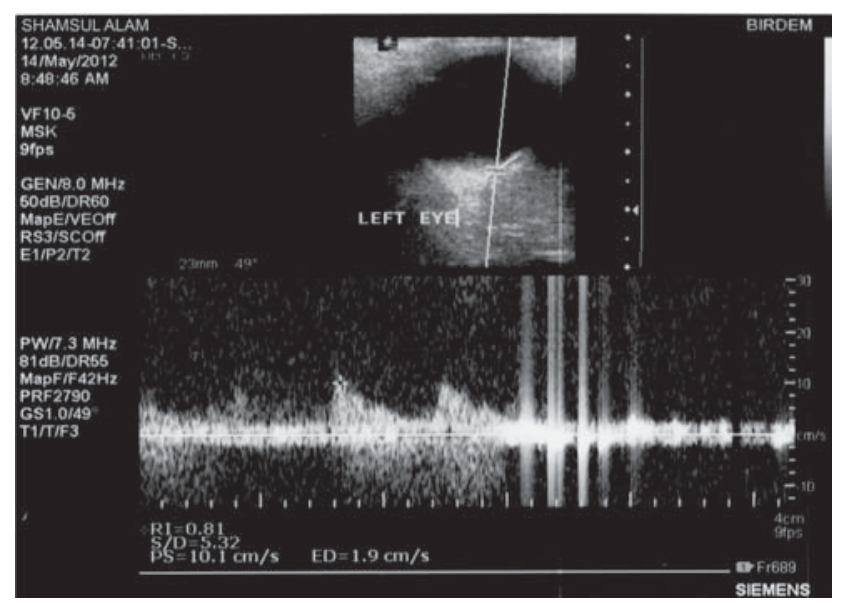

Fig 4. Spectral Doppler flow patterns of retinal artery of left eye in a type 2 diabetic subject

images along with information regarding the direction and velocity of blood flow. ${ }^{23}$ The present study was attempted to evaluate clinically diagnosed diabetic patients without retinopathy by measuring the retinal arterial RI and compare the result with normal healthy controls by duplex color Doppler study.

In this study the age of the patients ranged from 27 to 68 years with the maximum number of cases found in the 40-49 years age group. Observation reveals no statistically significant difference regarding mean age between cases and controls ( $\mathrm{p}>0.05)$. A similar study done by Kawagishi et al ${ }^{24}$ showed no significant difference between the two groups with respect of age.

In this study the mean difference of retinal arterial PSV in diabetic eyes without retinopathy and control eyes 
was statistically significant $(\mathrm{p}<0.01)$. One investigator Guthoff et $\mathrm{al}^{25}$ who compared the mean PSV of retinal artery in diabetic patients without retinopathy and healthy subjects also found significant difference in retinal arterial PSV between cases and controls.

The mean EDV of 160 diabetic eyes without retinopathy and 160 control eyes was statistically significant $(p<0.01)$. This observation is supported by the study done by Jack et a ${ }^{15}$ who has compared the mean EDV of diabetic patients and control group and discovered that there was statistically significant difference of mean retinal arterial EDV between cases and control groups.

In this study mean RI in 160 eyes of 80 diabetic patients without retinopathy was found $0.75 \pm 0.04(0.66-0.81)$. Kawagishi et $\mathrm{al}^{24}$ found the mean RI value $0.70 \pm$ 0.005 . Mean RI value measured in 160 eyes of 80 healthy subjects was $0.64 \pm 0.02(0.60-0.70)$ in this study and Kawagishi et $\mathrm{al}^{24}$ found the mean RI value $0.65 \pm 0.05$ in healthy subjects. So, the result of present study is consistent with the study done by Kawagishi et al. ${ }^{24}$

From the results of the present study it can be concluded that there is statistically significant difference between retinal arterial RI of type 2 diabetic patients without retinopathy and that of healthy control adult subjects included in this study. Higher RI in type 2 diabetics may predict the early hemodynamic changes in the retinal artery of these patients before the clinical onset of retinopathy. However, further studies including large number of study subjects are recommended.

\section{References}

1. Ahmed KR, Karim MN, Bhowmik B, Habib SH, Ali L. Incidence of diabetic retinopathy. J Diabetes 2012; 4: 386-391.

2. Shaw JE, Sieree RA, Zimmet PZ. Global estimates of the prevalence of diabetes. Diabetes Res Clin Prac 2010; 87(1): 4-14.

3. IDF Diabetes Atlas. Available at: http//www. idf.org/diabetesatlas/5e/the global burden. Accessed November 2012.

4. Yau JW, Rogers SL, Kawasaki R, Lamourese EL, Bek T. Global prevalence and major risk factors of diabetic retinopathy. Diabetes Care 2012; 35(3): 556-564.

5. Sandeman DD, Shore AC, Tooke JE. Relation of skin capillary pressure in patients with insulin-dependent diabetes to complications and metabolic control. N Engl J Med 1992; 327: 760-764.

6. Dandona R, Dandona L. Socioeconomic status and blindness. Br J Ophthalmol 2001; 85: 1484-1488.

7. Dandona R, Dandona L. Review findings from the Andhra Pradesh eye disease study. Indian J Ophthalmol 2001; 49: 215-234.

8. Mackinnon JR, McKillop G, Brien O, Butt Z, Nelson P. Colour Doppler imaging of the ocular circulation in diabetic retinopathy. Acta Ophthalmol 2000; 78: 386-389.

9. Mendivil A, Cuartero V, Mendivil MP. Ocular flow velocities in patients with proliferative diabetic retinopathy and healthy volunteers. B J of Ophthalmology 1995; 79: 413-416.

10. Dimitrova G. Colour Doppler imaging of ocular and orbital blood vessels in retinal diseases. European Ophthalmic Review 2011; 5: 16-19.

11. Fielding JA. Ultrasound imaging of the eye through the closed lid using a non dedicated scanner. Clin Radiol 1987; 38: 131-135.

12. Guthoff RF, Berger RW, Winkler P, Helmke K, Chumbley LC. Doppler ultrasonography of the ophthalmic and central retinal vessels. Arch Ophthalmol 1991; 109: 532-536.

13. Goebal W, Leib H, Sergott RC, Farhoumand R, Grehn F. Colour Doppler imaging: a new technique to assess orbital blood flow in patients with diabetic retinopathy. Invest Ophthalmol Vis C 1995; 36: 864-870.

14. Tamaki Y, Nagahara M, Yamashita H, Kikuchi M. Blood velocity in the ophthalmic artery determined by colour Doppler imaging in normal subjects and diabetics. Jpn J Ophthalmol 1993; 37: 385-392.

15. Jack PH. Colour Doppler ultrasonographic imaging of central retinal artery. Available at: http://www.resmedical.com/endocrine-glands/58571. Accessed April 2012.

16. Little HL. The role of abnormal hemodynamic in the pathogenesis of diabetic retinopathy. Trans Am Ophthalmol Soc 1976; 74: 573-636.

17. Eliash ZB, Nelsol DA, Barak A, Bartal O. Reduced retinal blood flow velocity in diabetes retinopathy. Retina 2010; 10: $1-11$.

18. Nagaoka A, Sato E, Takahashi A,Yokota H, Sogawa K, Yoshida A. Impaired retinal circulation in patients with type 2 diabetes mellitus: retinal laser Doppler velocimetry study. Invest Ophthalmol Vis Sci 2010; 51: 6729-6734.

19. Zawinka C, Dornar GT, Polska E, Frank B. Calculation of the diameter of the central retinal artery from non invasive measurements in human. Current Eye Research 2002; 25: 341-345. 
20. Polska E, Kircher K, Ehrlich P, Vecsei PV, Schmetterer L. $\mathrm{RI}$ in central retinal artery as assessed by CDI does not correspond to retinal vascular resistance. Am J Physiol Heart Circ Physiol 2001; 280(4): 1442-1447.

21. Dimitrova G. Colour Doppler imaging of ocular and orbital blood vessels in retinal diseases. European Ophthalmic Review 2011; 5: 16-19.

22. Prahs P, Helbig H. Diabetic eye disease. Ther Umsch 2009; 66: $183-188$.
23. Benden CJ, Abbitt PL, Beadless KA. Colour Doppler US of the orbit. Radio Graphic 1995; 15: 589-608.

24. Kawagishi T, Nishizawa Y, Emoto M, Konishi T, Maekawa $\mathrm{K}$, Hagiwara $\mathrm{S}$ et al. Impaired retinal artery blood flow in IDDM patients before clinical manifestations of diabetic retinopathy. Diabetes Care 1995; 18: 1544-1549.

25. Guthoff RF, Berger RW, Winkler P, Helmke K, Chumbley LC. Doppler ultrasonography of the ophthalmic and central retinal vessels. Arch Ophthalmol 1991; 109: 532-536. 